\title{
New Iterative Algorithm for Two Infinite Families of Multivalued Quasi-Nonexpansive Mappings in Uniformly Convex Banach Spaces
}

\author{
Fang Zhang, Huan Zhang, and Yulong Zhang \\ Department of Mathematics, Tianjin Polytechnic University, Tianjin 300387, China \\ Correspondence should be addressed to Fang Zhang; zhangfangsx@163.com
}

Received 30 November 2012; Accepted 14 May 2013

Academic Editor: D. R. Sahu

Copyright (C) 2013 Fang Zhang et al. This is an open access article distributed under the Creative Commons Attribution License, which permits unrestricted use, distribution, and reproduction in any medium, provided the original work is properly cited.

We introduce a new iterative scheme for finding a common fixed point of two countable families of multivalued quasi-nonexpansive mappings and prove a weak convergence theorem under the suitable control conditions in a uniformly convex Banach space. We also give a new proof method to the iteration in the paper of Abbas et al. (2011).

\section{Introduction}

A Banach space $E$ is said to be strictly convex if $\|x-y\| / 2<1$ for all $x, y \in E$ with $\|x\|=\|y\|=1$ and $x \neq y$. A Banach space $E$ is called uniformly convex if for each $\varepsilon>0$ there is a $\delta>0$ such that, for $x, y \in E$ with $\|x\|,\|y\| \leq 1$ and $\|x-y\| \geq \varepsilon$, $\|x+y\| \leq 2(1-\delta)$ holds. The modulus of convexity of $E$ is defined by

$$
\delta_{E}(\varepsilon)=\inf \left\{1-\left\|\frac{1}{2}(x+y)\right\|:\|x\|,\|y\| \leq 1,\|x-y\| \geq \varepsilon\right\},
$$

for all $\varepsilon \in[0,2]$. $E$ is uniformly convex if $\delta_{E}(0)=0$, and $\delta_{E}(\varepsilon)>0$ for all $0<\varepsilon<2$. It is known that every uniformly convex Banach space is strictly convex and reflexive. Let $S(E)=\{x \in E:\|x\|=1\}$. Then the norm of $E$ is said to be Gâteaux differentiable if

$$
\lim _{t \rightarrow 0} \frac{\|x+t y\|-\|x\|}{t}
$$

exists for each $x, y \in S(E)$. In this case $E$ is called smooth. The norm of $E$ is said to be Fréchet differentiable if for each $x \in S(E)$ the limit is attained uniformly for $y \in S(E)$. The norm of $E$ is called uniformly Fréchet differentiable if the limit is attained uniformly for $x, y \in S(E)$. It is well known that (uniform) Fréchet differentiability of the norm of $E$ implies (uniform) Gâteaux differentiability of the norm of $E$.
Let $\rho_{E}:[0, \infty) \rightarrow[0, \infty)$ be the modulus of smoothness of $E$ defined by

$$
\begin{aligned}
\rho_{E} & (t) \\
& =\sup \left\{\frac{1}{2}(\|x+y\|+\|x-y\|)-1: x \in S(E),\|y\| \leq t\right\} .
\end{aligned}
$$

A Banach space $E$ is said to be uniformly smooth if $\rho_{E}(t) / t \rightarrow 0$ as $t \rightarrow 0$. Suppose that $q>1$; then $E$ is said to be $q$-uniformly smooth if there exists $c>0$ such that $\rho_{E}(t)<c t^{q}$. It is easy to see that if $E$ is $q$-uniformly smooth, then $q \leq 2$ and $E$ is uniformly smooth. It is well known that $E$ is uniformly smooth if and only if the norm of $E$ is uniformly Fréchet differentiable, and hence the norm of $E$ is Fréchet differentiable. For more details, we refer the reader to Agarwal et al. [1] and Chidume et al. [2].

In recent years, many authors have done a lot of valuable research in Banach space. They extend some iterative schemes from Hilbert spaces to Banach spaces and obtain some convergence theorems which are very interesting and meaningful; see [3-5]. Moreover, a variety of mappings are considered by articles [3-9], including nonexpansive mappings, nonexpansive semigroup, strict pseudocontractions mappings, and total quasi- $\phi$-asymptotically nonexpansive mappings.

It is easy to know that the theory of multivalued nonexpansive mappings is harder than the corresponding theory 
of single-valued nonexpansive mappings. In 1969, Nadler [10] introduced multivalued contraction mapping and proved the corresponding convergence theorem. In 1973, Markin [11] first used the Hausdorff metric to study the fixed points for multivalued contractions and nonexpansive mappings. Later in 1997, Hu et al. [12] proved the convergence theorems for finding common fixed point of two multivalued nonexpansive mappings that satisfied certain contractive condition.

In 2005, Sastry and Babu [13] defined Mann and Ishikawa iterates for a multivalued mapping with a fixed point and proved that these iterates converge to a fixed point of the multivalued mapping under certain conditions. They have given an example that the fixed point generalized by limit of the sequence is different from the point of initial choice.

In 2011, Abbas et al. [14] introduced a new one-step iterative process to approximate common fixed points of two multivalued nonexpansive mappings in a real uniformly convex Banach space. Let $S, T: K \rightarrow C B(K)$ be two multivalued nonexpansive mappings. They introduced iteration as follows:

$$
\begin{gathered}
x_{0} \in K \quad \text { chosen arbitrarily, } \\
x_{n+1}=a_{n} x_{n}+b_{n} y_{n}+c_{n} z_{n}, \quad n \in N,
\end{gathered}
$$

where $y_{n} \in T x_{n}$ and $z_{n} \in S x_{n}$ such that $\left\|y_{n}-p\right\| \leq d\left(p, S x_{n}\right)$ and $\left\|z_{n}-p\right\| \leq d\left(p, T x_{n}\right)$ for $p \in F(T) \cap F(S)$, and $a_{n}, b_{n}$, $c_{n} \in(0,1)$ satisfying $a_{n}+b_{n}+c_{n} \leq 1$. Then they obtained strong convergence theorems for the proposed process under some basic boundary conditions.

In 2012, Chang et al. [15], for solving the convex feasibility problems for an infinite family of quasi- $\phi$-asymptotically nonexpansive mappings, used the modified block iterative method and obtained some strong convergence theorems under suitable conditions in Banach space.

In the same year, Bunyawat and Suantai [16] introduced an iterative method for finding a common fixed point of a countable family of multivalued quasi-nonexpansive mapping in a uniformly convex Banach space. They proved that the iterative sequence generated by their proposed method is an approximating fixed point sequence of the multivalued quasi-nonexpansive mapping under certain control conditions, and they got some strong convergence theorems of their proposed method.

Phuangphoo and Kumam [9] extended and improved the above results in 2012. They introduced a new iterative procedure which was constructed by the shrinking hybrid projection method for solving the common solution of fixed point problems for two total quasi- $\phi$-asymptotically nonexpansive multivalued mappings. Under suitable conditions, the strong convergence theorems were established in a uniformly smooth and strictly convex real Banach space with Kadec-Klee property.

Different iterative processes have been used to approximate fixed points of multivalued mappings. Many authors have intensively studied the fixed point theorems and got some results. At the same time, they extended this result to many discipline branches, such as control theory, convex optimization, variational inequalities, differential inclusion, and economics (see [3-9, 17-22]).
Motivated by the above authors, we generalize and modify the hybrid block iterative algorithm (see [23]) for two countable families of multivalued quasi-nonexpansive mappings in a uniformly convex Banach space. First we prove that the sequence generated by our iterative method is weak convergence under the property conditions. Then we use compact space to prove the strong convergence in a uniformly convex Banach space. As expected, we got some weak and strong convergence theorems about the common fixed point of two countable families of multivalued quasi-nonexpansive mappings in a uniformly convex Banach space.

\section{Preliminaries}

Let $E$ be a real Banach space. A subset $C$ of $E$ is called proximinal if for each $x \in E$ there exists an element $k \in C$ such that

$$
d(x, k)=d(x, C),
$$

where $d(x, C)=\inf _{y \in C}\|x-y\|$ is the distance from the point $x$ to the set $C$. It is not hard to known that weakly compact convex subsets of a Banach space and closed convex subsets of a uniformly convex Banach space are proximinal.

A map $T: E \rightarrow C B(E)$ is called hemicompact if, for any sequence $\left\{x_{n}\right\}$ in $E$ such that $d\left(x_{n}, T x_{n}\right) \rightarrow 0$ as $n \rightarrow \infty$, there exists a subsequence $\left\{x_{n_{k}}\right\}$ of $\left\{x_{n}\right\}$ such that $x_{n_{k}} \rightarrow$ $p \in E$. We note that if $E$ is compact, then every multivalued mapping $T$ is hemicompact.

Let $E$ be a real Banach space. We denote $C B(E)$ as the class of all nonempty bounded and closed subsets of $E$ (see $[10])$, and denote $P(E)$ as the family of nonempty bounded proximinal subsets of $E$. The Hausdorff metric induced by the metric $d$ of $E$ is defined by

$$
H(A, B)=\max \left\{\sup _{x \in A} d(x, B), \sup _{y \in B} d(y, A)\right\},
$$

for all $A, B \in C B(E)$.

For a single-valued mapping $T$, a point $p$ is called a fixed point of $T$ if $p=T p$. For a multivalued mapping $T$, a point $p$ is called a fixed point of $T$ if $p \in T p$. The set of fixed points of $T$ is denoted by $F(T)$.

Let $E$ be a uniformly convex real Banach space, and let $K$ be a nonempty closed convex subset of $E$. A multivalued mapping $T: K \rightarrow C B(K)$ is said to be

(i) a contraction if there exists a constant $k \in[0,1)$ such that

$$
H(T x, T y) \leq k\|x-y\|, \quad \forall x, y \in K ;
$$

(ii) nonexpansive if

$$
H(T x, T y) \leq\|x-y\|, \quad \forall x, y \in K ;
$$

(iii) quasi-nonexpansive if $F(T) \neq \emptyset$ and

$$
H(T x, T p) \leq\|x-p\|, \quad \forall x \in K, \forall p \in F(T) .
$$


It is well known that every nonexpansive multivalued mapping $T$ with $F(T) \neq \emptyset$ is multivalued quasi-nonexpansive. But there exist multivalued quasi-nonexpansive mappings that are not multivalued nonexpansive. It is clear that if $T$ is a quasi-nonexpansive multivalued mapping, then $F(T)$ is closed.

A Banach space $E$ is said to satisfy Opial's condition if whenever $\left\{x_{n}\right\}$ is a sequence in $E$ which converges weakly to $x$, then

$$
\limsup _{n \rightarrow \infty}\left\|x_{n}-x\right\|<\limsup _{n \rightarrow \infty}\left\|x_{n}-y\right\|, \quad \forall y \in E, x \neq y .
$$

Lemma 1 (see Chang et al. [15]). Let $E$ be a uniformly convex Banach space, $r>0$ a positive number, and $B_{r}(0)$ a closed ball of $E$. Then, for any given sequence $\left\{x_{i}\right\}_{i=1}^{\infty} \subset B_{r}(0)$ and for any given sequence $\left\{\lambda_{i}\right\}_{i=1}^{\infty}$ of positive number with $\sum_{n=1}^{\infty} \lambda_{n}=$ 1 , there exists a continuous, strictly increasing, and convex function $g:[0,2 r) \rightarrow[0, \infty)$ with $g(0)=0$ such that, for any positive integer $i, j$ with $i \neq j$,

$$
\left\|\sum_{n=1}^{\infty} \lambda_{n} x_{n}\right\|^{2} \leq \sum_{n=1}^{\infty} \lambda_{n}\left\|x_{n}\right\|^{2}-\lambda_{i} \lambda_{j} g\left(\left\|x_{i}-x_{j}\right\|\right) .
$$

Lemma 2 (see Schu [24]). Suppose that $E$ is a uniformly convex Banach space and $0<p \leq t_{n} \leq q<1$ for all positive integers $n$. Also suppose that $\left\{x_{n}\right\}$ and $\left\{y_{n}\right\}$ are two sequences of E such that $\lim \sup _{n \rightarrow \infty}\left\|x_{n}\right\| \leq r, \limsup _{n \rightarrow \infty}\left\|y_{n}\right\| \leq r$, and $\lim _{n \rightarrow \infty}\left\|t_{n} x_{n}+\left(1-t_{n}\right) y_{n}\right\|=r$ hold for some $r \geq 0$. Then $\lim _{n \rightarrow \infty}\left\|x_{n}-y_{n}\right\|=0$.

Lemma 3 (see Liu [25] and Xu [26]). Let $\left\{a_{n}\right\}$ be a sequence of nonnegative real numbers satisfying the following property:

$$
a_{n+1} \leq\left(1-t_{n}\right) a_{n}+b_{n}+t_{n} c_{n}
$$

where $\left\{t_{n}\right\},\left\{b_{n}\right\}$, and $\left\{c_{n}\right\}$ satisfy the following restrictions:

(i) $\sum_{n=0}^{\infty} t_{n}=\infty$;

(ii) $\sum_{n=0}^{\infty} b_{n}<\infty$;

(iii) $\lim \sup _{n \rightarrow \infty} c_{n} \leq 0$

Then, $\left\{a_{n}\right\}$ converges to zero as $n \rightarrow \infty$.

\section{Weak Convergence Theorem}

In this section, we prove the weak convergence theorems for finding a common element in common set of fixed sets of two infinite families of multivalued quasi-nonexpansive mappings in a Banach space.

Theorem 4. Let $C$ be a nonempty closed convex subset of a uniformly convex Banach space $E$ with Opial's condition. For $i \in N$, let $\left\{T_{i}\right\}$ and $\left\{S_{i}\right\}$ be two sequences of multivalued quasi-nonexpansive mappings from $C$ into $P(C)$ with
$F:=\left[\bigcap_{i=1}^{\infty} F\left(T_{i}\right)\right] \cap\left[\bigcap_{i=1}^{\infty} F\left(S_{i}\right)\right] \neq \emptyset$ and $p \in F$. Let $\left\{x_{n}\right\}$ be a sequence defined by

$$
\begin{gathered}
x_{0} \in C \quad \text { chosen arbitrarily, } \\
x_{n+1}=\alpha_{n, 0} x_{n}+\sum_{i=1}^{\infty} \alpha_{n, i} y_{n, i}, \\
y_{n}=\beta_{n, 0} x_{n}+\sum_{i=1}^{\infty} \beta_{n, i} x_{n, i},
\end{gathered}
$$

where $y_{n, i} \in T_{i} y_{n}$ such that $d\left(p, y_{n, i}\right)=d\left(p, T_{i} y_{n}\right)$ and $x_{n, i} \in S_{i} x_{n}$ such that $d\left(p, x_{i, n}\right)=d\left(p, S_{i} x_{n}\right),\left\{\alpha_{n, i}\right\}_{i=0}^{\infty}$ and $\left\{\beta_{n, i}\right\}_{i=0}^{\infty}$ are sequences in $[0,1]$ which satisfies $\sum_{i=0}^{\infty} \alpha_{n, i}=1$ and $\sum_{i=0}^{\infty} \beta_{n, i}=1, \limsup _{n \rightarrow \infty} \alpha_{n, 0}<1, \liminf _{n \rightarrow \infty} \alpha_{n, 0} \alpha_{n, j}>0$, and $\liminf _{n \rightarrow \infty} \beta_{n, 0} \beta_{n, i}>0$ for $i \in N$. Then $\left\{x_{n}\right\}$ converges weakly to a point $u \in F$.

Proof. First we prove that $\left\{x_{n}\right\}$ is bounded and $\lim _{n \rightarrow \infty} \| x_{n}-$ $p \|$ exists for each $p \in F$. In fact, from Lemma 2, (13), and $T_{i}$ and $S_{i}$ both being multivalued quasi-nonexpansive mappings, we have that

$$
\begin{aligned}
\| y_{n}- & p \|^{2} \\
= & \left\|\beta_{n, 0}\left(x_{n}-p\right)+\sum_{i=1}^{\infty} \beta_{n, i}\left(x_{n, i}-p\right)\right\|^{2} \\
\leq & \beta_{n, 0}\left\|x_{n}-p\right\|^{2}+\sum_{i=1}^{\infty} \beta_{n, i}\left\|x_{n, i}-p\right\|^{2} \\
& -\beta_{n, 0} \beta_{n, j} g\left(\left\|x_{n}-x_{n, j}\right\|\right) \\
= & \beta_{n, 0}\left\|x_{n}-p\right\|^{2}+\sum_{i=1}^{\infty} \beta_{n, i}\left(d\left(S_{i} x_{n}, p\right)\right)^{2} \\
& -\beta_{n, 0} \beta_{n, j} g\left(\left\|x_{n}-x_{n, j}\right\|\right) \\
\leq & \beta_{n, 0}\left\|x_{n}-p\right\|^{2}+\sum_{i=1}^{\infty} \beta_{n, i}\left(H\left(S_{i} x_{n}, p\right)\right)^{2} \\
& -\beta_{n, 0} \beta_{n, j} g\left(\left\|x_{n}-x_{n, j}\right\|\right) \\
\leq & \beta_{n, 0}\left\|x_{n}-p\right\|^{2}+\sum_{i=1}^{\infty} \beta_{n, i}\left\|x_{n}-p\right\|^{2} \\
& -\beta_{n, 0} \beta_{n, j} g\left(\left\|x_{n}-x_{n, j}\right\|\right) \\
& \left\|x_{n}-p\right\|^{2}-\beta_{n, 0} \beta_{n, j} g\left(\left\|x_{n}-x_{n, j}\right\|\right),
\end{aligned}
$$

$$
\begin{aligned}
& \left\|x_{n+1}-p\right\|^{2} \\
& =\left\|\alpha_{n, 0}\left(x_{n}-p\right)+\sum_{i=1}^{\infty} \alpha_{n, i}\left(y_{n, i}-p\right)\right\|^{2} \\
& \leq \alpha_{n, 0}\left\|x_{n}-p\right\|^{2}+\sum_{i=1}^{\infty} \alpha_{n, i}\left\|y_{n, i}-p\right\|^{2}
\end{aligned}
$$




$$
\begin{aligned}
= & \alpha_{n, 0}\left\|x_{n}-p\right\|^{2}+\sum_{i=1}^{\infty} \alpha_{n, i}\left(d\left(T_{i} y_{n}, p\right)\right)^{2} \\
\leq & \alpha_{n, 0}\left\|x_{n}-p\right\|^{2}+\sum_{i=1}^{\infty} \alpha_{n, i}\left(H\left(T_{i} y_{n}, p\right)\right)^{2} \\
\leq & \alpha_{n, 0}\left\|x_{n}-p\right\|^{2}+\sum_{i=1}^{\infty} \alpha_{n, i}\left\|y_{n}-p\right\|^{2} \\
\leq & \alpha_{n, 0}\left\|x_{n}-p\right\|^{2} \\
& +\sum_{i=1}^{\infty} \alpha_{n, i}\left(\left\|x_{n}-p\right\|^{2}-\beta_{n, 0} \beta_{n, j} g\left(\left\|x_{n}-x_{n, j}\right\|\right)\right) \\
= & \left\|x_{n}-p\right\|^{2}-\sum_{i=1}^{\infty} \alpha_{n, i} \beta_{n, 0} \beta_{n, j} g\left(\left\|x_{n}-x_{n, j}\right\|\right) \\
= & \left\|x_{n}-p\right\|^{2}-\left(1-\alpha_{n, 0}\right) \beta_{n, 0} \beta_{n, j} g\left(\left\|x_{n}-x_{n, j}\right\|\right) .
\end{aligned}
$$

From (15) we have that $\left\{\left\|x_{n}-p\right\|\right\}$ is nondecreasing and bounded by induction, so $\left\{x_{n}\right\}$ is bounded and $\lim _{n \rightarrow \infty} \| x_{n}-$ $p \|$ exists.

Next we prove that $\lim _{n \rightarrow \infty}\left\|x_{n}-x_{n, j}\right\|=0$ and $\lim _{n \rightarrow \infty}\left\|y_{n}-y_{n, j}\right\|=0$. Indeed, we can rewrite (15) as follows:

$$
\begin{gathered}
\left(1-\alpha_{n, 0}\right) \beta_{n, 0} \beta_{n, j} g\left(\left\|x_{n}-x_{n, j}\right\|\right) \\
\leq\left\|x_{n}-p\right\|^{2}-\left\|x_{n+1}-p\right\|^{2} .
\end{gathered}
$$

Since $\lim \sup _{n \rightarrow \infty} \alpha_{n, 0}<1, \liminf _{n \rightarrow \infty} \beta_{n, 0} \beta_{n, j}>0$, and $\lim _{n \rightarrow \infty}\left\|x_{n}-p\right\|$ exists, we have $\lim _{n \rightarrow \infty} g\left(\left\|x_{n}-x_{n, j}\right\|\right)=0$; by the property of $g$, we also get that

$$
\lim _{n \rightarrow \infty}\left\|x_{n}-x_{n, j}\right\|=0
$$

for each $j \in N$. From (13) we have

$$
\begin{aligned}
\left\|y_{n}-x_{n}\right\| & =\left\|\beta_{n, 0} x_{n}+\sum_{i=1}^{\infty} \beta_{n, i} x_{n, i}-x_{n}\right\| \\
& \leq \sum_{i=1}^{\infty} \beta_{n, i}\left\|x_{n, i}-x_{n}\right\| .
\end{aligned}
$$

Together with (17), we have

$$
\lim _{n \rightarrow \infty}\left\|y_{n}-x_{n}\right\|=0
$$

On the other hand, from (14) and Lemma 1, we have

$$
\begin{aligned}
\left\|x_{n+1}-p\right\|^{2} & \left\|\alpha_{n, 0}\left(x_{n}-p\right)+\sum_{i=1}^{\infty} \alpha_{n, i}\left(y_{n, i}-p\right)\right\|^{2} \\
\leq & \alpha_{n, 0}\left\|x_{n}-p\right\|^{2}+\sum_{i=1}^{\infty} \alpha_{n, i}\left\|y_{n, i}-p\right\|^{2} \\
& -\alpha_{n, 0} \alpha_{n, j} g\left(\left\|x_{n}-y_{n, j}\right\|\right) \\
= & \alpha_{n, 0}\left\|x_{n}-p\right\|^{2}+\sum_{i=1}^{\infty} \alpha_{n, i}\left(d\left(T_{i} y_{n}, p\right)\right)^{2} \\
& -\alpha_{n, 0} \alpha_{n, j} g\left(\left\|x_{n}-y_{n, j}\right\|\right) \\
\leq & \alpha_{n, 0}\left\|x_{n}-p\right\|^{2}+\sum_{i=1}^{\infty} \alpha_{n, i}\left(H\left(T_{i} y_{n}, p\right)\right)^{2} \\
& -\alpha_{n, 0} \alpha_{n, j} g\left(\left\|x_{n}-y_{n, j}\right\|\right) \\
& -\alpha_{n, 0} \alpha_{n, j} g\left(\left\|x_{n}-p\right\|^{2}+\sum_{n}^{\infty} \alpha_{n, i}\left\|x_{n}-p\right\|^{2} \|\right) \\
\leq & \alpha_{n, 0}\left\|x_{n}-p\right\|^{2}+\sum_{i=1}^{\infty} \alpha_{n, i}\left\|y_{n}-p\right\|^{2} \\
& -\alpha_{n, 0} \alpha_{n, j} g\left(\left\|x_{n}-y_{n, j}\right\|\right) \\
& \\
& \\
&
\end{aligned}
$$

Then, we can rewrite (20) as follows:

$$
\alpha_{n, 0} \alpha_{n, j} g\left(\left\|x_{n}-y_{n, j}\right\|\right) \leq\left\|x_{n}-p\right\|^{2}-\left\|x_{n+1}-p\right\|^{2} .
$$

Since $\lim \inf _{n \rightarrow \infty} \alpha_{n, 0} \alpha_{n, j}>0$ and $\lim _{n \rightarrow \infty}\left\|x_{n}-p\right\|$ exists, we have $\lim _{n \rightarrow \infty} g\left(\left\|x_{n}-y_{n, j}\right\|\right)=0$; by the property of $g$, we also get that

$$
\lim _{n \rightarrow \infty}\left\|x_{n}-y_{n, j}\right\|=0 \text {, }
$$

for each $j \in N$. By the triangle inequality, we have

$$
\left\|y_{n}-y_{n, j}\right\| \leq\left\|y_{n}-x_{n}\right\|+\left\|x_{n}-y_{n, j}\right\|
$$

Together with (19) and (22), we get that

$$
\lim _{n \rightarrow \infty}\left\|y_{n}-y_{n, j}\right\|=0 \text {. }
$$

Now we prove that $\left\{x_{n}\right\}$ converges weakly to a point $u \in F$. Since $\left\{x_{n}\right\}$ is bounded, so there exists a subsequence $\left\{x_{n_{k}}\right\}_{k=1}^{\infty}$ of $\left\{x_{n}\right\}_{n=1}^{\infty}$ such that $x_{n_{k}} \rightarrow u$ for some $u \in C$; from (19) we 
have $y_{n_{k}} \rightarrow u$. Suppose that there exists $i \in N$ such that $T_{i} u \neq u$ and $S_{i} u \neq u$. By Opial's condition, we have that

$$
\begin{aligned}
& \limsup _{k \rightarrow \infty}\left\|x_{n_{k}}-u\right\|<\limsup _{k \rightarrow \infty}\left\|x_{n_{k}}-S_{i} u\right\|, \\
& \limsup _{k \rightarrow \infty}\left\|y_{n_{k}}-u\right\|<\underset{k \rightarrow \infty}{\limsup }\left\|y_{n_{k}}-T_{i} u\right\| .
\end{aligned}
$$

From $T_{i}$ and $S_{i}$ both being two multivalued quasinonexpansive mappings, we have that

$$
\begin{aligned}
& \left\|x_{n_{k}}-S_{i} u\right\| \\
& \leq\left\|x_{n_{k}}-x_{n_{k}, i}\right\|+\left\|x_{n_{k}, i}-S_{i} u\right\| \\
& \quad=\left\|x_{n_{k}}-x_{n_{k}, i}\right\|+d\left(S_{i} x_{n_{k}}, S_{i} u\right) \\
& \leq\left\|x_{n_{k}}-x_{n_{k}, i}\right\|+H\left(S_{i} x_{n_{k}}, S_{i} u\right) \\
& \quad \leq\left\|x_{n_{k}}-x_{n_{k}, i}\right\|+\left\|x_{n_{k}}-u\right\|, \\
& \left\|y_{n_{k}}-T_{i} u\right\| \\
& \leq\left\|y_{n_{k}}-y_{n_{k}, i}\right\|+\left\|y_{n_{k}, i}-T_{i} u\right\| \\
& \quad=\left\|y_{n_{k}}-y_{n_{k}, i}\right\|+d\left(T_{i} y_{n_{k}}, T_{i} u\right) \\
& \quad \leq\left\|y_{n_{k}}-y_{n_{k}, i}\right\|+H\left(T_{i} y_{n_{k}}, T_{i} u\right) \\
& \quad \leq\left\|y_{n_{k}}-y_{n_{k}, i}\right\|+\left\|y_{n_{k}}-u\right\| .
\end{aligned}
$$

Taking limsup $\operatorname{su}_{k \rightarrow \infty}$ on both sides of (27) and (28), respectively, from (17) and (24), we get that

$$
\begin{aligned}
& \limsup _{k \rightarrow \infty}\left\|x_{n_{k}}-S_{i} u\right\| \\
& \leq \limsup _{k \rightarrow \infty}\left(\left\|x_{n_{k}}-x_{n_{k}, i}\right\|+\left\|x_{n_{k}}-u\right\|\right) \\
& \leq \limsup _{k \rightarrow \infty}\left\|x_{n_{k}}-x_{n_{k}, i}\right\|+\limsup _{k \rightarrow \infty}\left\|x_{n_{k}}-u\right\| \\
& =\limsup _{k \rightarrow \infty}\left\|x_{n_{k}}-u\right\| \text {, } \\
& \limsup _{k \rightarrow \infty}\left\|y_{n_{k}}-T_{i} u\right\| \\
& \leq \limsup _{k \rightarrow \infty}\left(\left\|y_{n_{k}}-y_{n_{k}, i}\right\|+\left\|y_{n_{k}}-u\right\|\right) \\
& \leq \underset{k \rightarrow \infty}{\limsup }\left\|y_{n_{k}}-y_{n_{k}, i}\right\|+\limsup _{k \rightarrow \infty}\left\|y_{n_{k}}-u\right\| \\
& =\limsup _{k \rightarrow \infty}\left\|y_{n_{k}}-u\right\| \text {. }
\end{aligned}
$$

Combining (25) with (29) and combining (26) with (30), respectively, we get that

$$
\begin{gathered}
\underset{k \rightarrow \infty}{\limsup }\left\|x_{n_{k}}-u\right\|<\limsup _{k \rightarrow \infty}\left\|x_{n_{k}}-u\right\|, \\
\underset{k \rightarrow \infty}{\limsup }\left\|y_{n_{k}}-u\right\|<\underset{k \rightarrow \infty}{\limsup }\left\|y_{n_{k}}-u\right\|,
\end{gathered}
$$

a contradiction. So we have $u=T_{i} u$ and $u=S_{i} u$ for all $i \in N$ by the proof of contradiction; this means that $u \in F$. Next we prove that $\left\{x_{n}\right\}$ converges weakly to $u$. Take another subsequence $\left\{x_{m_{k}}\right\}_{k=1}^{\infty}$ of $\left\{x_{n}\right\}$ such that $x_{m_{k}} \rightarrow v$, for some $v \in C$. Again, as above, we conclude that $v \in F$. Now we show that $u=v$. We assume that $u \neq v$, since $\lim _{n \rightarrow \infty}\left\|x_{n}-p\right\|$ exists for every $p \in F$. By (10) we have that

$$
\begin{aligned}
& \lim _{n \rightarrow \infty}\left\|x_{n}-u\right\| \\
& \quad=\limsup _{k \rightarrow \infty}\left\|x_{n_{k}}-u\right\|<\underset{k \rightarrow \infty}{\limsup }\left\|x_{n_{k}}-v\right\| \\
& \quad=\limsup _{k \rightarrow \infty}\left\|x_{m_{k}}-v\right\|<\underset{k \rightarrow \infty}{\limsup }\left\|x_{m_{k}}-u\right\| \\
& =\lim _{n \rightarrow \infty}\left\|x_{n}-u\right\|,
\end{aligned}
$$

which means that $\lim _{n \rightarrow \infty}\left\|x_{n}-u\right\|<\lim _{n \rightarrow \infty}\left\|x_{n}-u\right\|$, a contradiction. So we get that $u=v$. Thus $x_{n} \rightarrow u$ as $n \rightarrow \infty$. The proof is complete.

Remark 5. Motivated by $[6,7,9,14,23]$, Theorem 4 improves and extends the following senses.

(1) For the mappings, we extend the mappings from nonexpansive mappings to quasi-nonexpansive multivalued mappings.

(2) We extend all single-valued mappings to multi-valued mappings.

(3) We extend two nonexpansive mappings or a countable family of mappings to two countable families of multivalued quasi-nonexpansive mappings.

If $T_{i}=T, S_{i}=S$ for each $i \in N$, then Theorem 4 is reduced to the following corollary.

Corollary 6. Let $C$ be a nonempty closed convex subset of a uniformly convex Banach space E with Opial's condition. Let T and $S$ be two multivalued quasi-nonexpansive mappings from $C$ into $P(C)$ with $F:=F(T) \cap F(S) \neq \emptyset$ and $p \in F$. Let $\left\{x_{n}\right\}$ be a sequence defined by

$$
\begin{aligned}
& x_{0} \in C \quad \text { chosen arbitrarily, } \\
& x_{n+1}=\alpha_{n} x_{n}+\left(1-\alpha_{n}\right) T y_{n}, \\
& y_{n}=\beta_{n} x_{n}+\left(1-\beta_{n}\right) S x_{n},
\end{aligned}
$$

where $y_{n} \in T y_{n}$ such that $d\left(p, y_{n}\right)=d\left(p, T y_{n}\right)$ and $x_{n} \in S x_{n}$ such that $d\left(p, x_{n}\right)=d\left(p, S x_{n}\right),\left\{\alpha_{n}\right\}$ and $\left\{\beta_{n}\right\}$ are sequences in $[0,1]$ which satisfies $\lim _{\sup _{n \rightarrow \infty}} \alpha_{n}<1, \liminf _{n \rightarrow \infty} \alpha_{n}(1-$ $\left.\alpha_{n}\right)>0$, and $\liminf _{n \rightarrow \infty} \beta_{n}\left(1-\beta_{n}\right)>0$. Then $\left\{x_{n}\right\}$ converges weakly to a point $u \in F$.

Theorem 7. Let $C$ be a nonempty compact convex subset of a uniformly convex Banach space E. For $i \in N$, let $\left\{S_{i}\right\}$ be a sequence of multivalued quasi-nonexpansive mappings from $C$ 
into $P(C)$ with $F:=\bigcap_{i=1}^{\infty} F\left(S_{i}\right) \neq \emptyset$ and $p \in F$. Let $\left\{x_{n}\right\}$ be a sequence defined by

$$
\begin{aligned}
& x_{0} \in C \quad \text { chosen arbitrarily, } \\
& x_{n+1}=\beta_{n, 0} x_{n}+\sum_{i=1}^{\infty} \beta_{n, i} x_{n, i},
\end{aligned}
$$

where $x_{n, i} \in S_{i} x_{n}$ such that $d\left(p, x_{i, n}\right)=d\left(p, S_{i} x_{n}\right),\left\{\beta_{n, i}\right\}_{i=0}^{\infty}$ is a sequence in $[0,1]$ which satisfies $\sum_{i=0}^{\infty} \beta_{n, i}=1$, and $\liminf _{n \rightarrow \infty} \beta_{n, 0} \beta_{n, i}>0$ for $i \in N$. Then $\left\{x_{n}\right\}$ converges strongly to a point $u \in F$.

Proof. Put $T_{i}=I$ and $\alpha_{n, 0}=0$ for all $n, i \in N$ in Theorem 4; then the conclusion of Theorem 7 is obtained.

\section{Strong Convergence Theorem}

In this section, we give a new proof method to iteration (4) in the basis of [14], and this proof method is easier than the one in [14].

Lemma 8 (see Abbas et al. [14]). Let $X$ be a uniformly convex Banach space and $K$ a nonempty closed convex subset of $X$. Let $S, T: K \rightarrow C(K)$ be multivalued nonexpansive mappings and $F \neq \emptyset$. Then for the sequence $\left\{x_{n}\right\}$ in (4), one has that $\lim _{n \rightarrow \infty}\left\|x_{n}-p\right\|$ exists for each $p \in F$, and $\lim _{n \rightarrow \infty} d\left(x_{n}, S x_{n}\right)=0=\lim _{n \rightarrow \infty} d\left(x_{n}, T x_{n}\right)$.

Theorem 9. Let $K$ be a closed convex subset of a real Banach space $X$, and let $S$ and $T$ assume bounded values, and let $\left\{x_{n}\right\}$ be as in Lemma 8. Then $\left\{x_{n}\right\}$ converges strongly to a common fixed point of $F$.

Proof. Since $C(K)$ is a nonempty compact subset of $K$ and $\left\{x_{n}\right\} \subset C(K)$, so there exists a subsequence $\left\{x_{n_{k}}\right\}$ of $\left\{x_{n}\right\}$ such that $\lim _{k \rightarrow \infty}\left\|x_{n_{k}}-q\right\|=0$ for some $q \in K$. Thus, it follows by Lemma 8 we have that

$$
\begin{aligned}
& d(q, T q) \\
& \quad \leq d\left(q, x_{n_{k}}\right)+d\left(x_{n_{k}}, T x_{n_{k}}\right)+H\left(T x_{n_{k}}, T q\right) \\
& \quad \leq 2\left\|x_{n_{k}}-q\right\|+d\left(x_{n_{k}}, T x_{n_{k}}\right) \longrightarrow 0 \text { as } k \longrightarrow \infty \\
& d(q, S q) \\
& \quad \leq d\left(q, x_{n_{k}}\right)+d\left(x_{n_{k}}, S x_{n_{k}}\right)+H\left(S x_{n_{k}}, S q\right) \\
& \quad \leq 2\left\|x_{n_{k}}-q\right\|+d\left(x_{n_{k}}, S x_{n_{k}}\right) \longrightarrow 0 \text { as } k \longrightarrow \infty .
\end{aligned}
$$

Hence $q \in F$. By Lemma $8, \lim _{n \rightarrow \infty}\left\|x_{n}-q\right\|$ exists. Hence $\lim _{n \rightarrow \infty} x_{n}=q$. The proof is complete.

\section{Acknowledgment}

The authors are grateful for the reviewers for their careful reading of the paper and for their suggestions which improved the quality of this work.

\section{References}

[1] R. P. Agarwal, D. O'Regan, and D. R. Sahu, Fixed Point Theory for Lipschitzian-Type Mappings with Applications, vol. 6 of Topological Fixed Point Theory and Its Applications, Springer, New York, NY, USA, 2009.

[2] C. E. Chidume, Geometric Properties of Banach Spaces and Nonlinear Iterations, Lecture Notes in Mathematics, Springer, New York, NY, USA, 2009.

[3] P. Sunthrayuth and P. Kumam, "A general iterative algorithm for the solution of variational inequalities for a nonexpansive semigroup in Banach spaces," Journal of Nonlinear Analysis and Optimization, vol. 1, no. 1, pp. 139-150, 2010.

[4] P. Sunthrayuth and P. Kumam, "Iterative methods for variational inequality problems and fixed point problems of a countable family of strict pseudo-contractions in a $q$-uniformly smooth Banach space," Fixed Point Theory and Applications, vol. 2012, article 65, 2012.

[5] P. Sunthrayuth and P. Kumam, "Viscosity approximation methods base on generalized contraction mappings for a countable family of strict pseudo-contractions, a general system of variational inequalities and a generalized mixed equilibrium problem in Banach spaces," Mathematical and Computer Modelling, 2013.

[6] P. Katchang and P. Kumam, "Strong convergence of the modified Ishikawa iterative method for infinitely many nonexpansive mappings in Banach spaces," Computers \& Mathematics with Applications, vol. 59, no. 4, pp. 1473-1483, 2010.

[7] P. Sunthrayuth and P. Kumam, "Strong convergence theorems of a general iterative process for two nonexpansive mappings in Banach spaces," Journal of Computational Analysis and Applications, vol. 14, no. 3, pp. 446-457, 2012.

[8] P. Sunthrayuth and P. Kumam, "A new composite general iterative scheme for nonexpansive semigroups in Banach spaces," International Journal of Mathematics and Mathematical Sciences, vol. 2011, Article ID 560671, 18 pages, 2011.

[9] P. Phuangphoo and P. Kumam, "An iterative procedure for solving the common solution of two total quasi- $\phi$-asymptotically nonexpansive multi-valued mappings in Banach spaces," Journal of Applied Mathematics and Computing, 2012.

[10] S. B. Nadler Jr., "Multi-valued contraction mappings," Pacific Journal of Mathematics, vol. 30, pp. 475-488, 1969.

[11] J. T. Markin, "Continuous dependence of fixed point sets," Proceedings of the American Mathematical Society, vol. 38, pp. 545-547, 1973.

[12] T. Hu, J. C. Huang, and B. E. Rhoades, "A general principle for Ishikawa iterations for multi-valued mappings," Indian Journal of Pure and Applied Mathematics, vol. 28, no. 8, pp. 1091-1098, 1997.

[13] K. P. R. Sastry and G. V. R. Babu, "Convergence of Ishikawa iterates for a multi-valued mapping with a fixed point," Czechoslovak Mathematical Journal, vol. 55(130), no. 4, pp. 817-826, 2005.

[14] M. Abbas, S. H. Khan, A. R. Khan, and R. P. Agarwal, "Common fixed points of two multivalued nonexpansive mappings by onestep iterative scheme," Applied Mathematics Letters, vol. 24, no. 2, pp. 97-102, 2011.

[15] S. S. Chang, J. K. Kim, and X. R. Wang, "Modified block iterative algorithm for solving convex feasibility problems in Banach spaces," Journal of Inequalities and Applications, vol. 2010, Article ID 869684, 14 pages, 2010. 
[16] A. Bunyawat and S. Suantai, "Convergence theorems for infinite family of multivalued quasi-nonexpansive mappings in uniformly convex Banach spaces," Abstract and Applied Analysis, vol. 2012, Article ID 435790, 6 pages, 2012.

[17] L. Górniewicz, Topological Fixed Point Theory of Multivalued Mappings, vol. 495 of Mathematics and Its Applications, Kluwer Academic, Dordrecht, The Netherlands, 1999.

[18] M. Abbas and B. E. Rhoades, "Fixed point theorems for two new classes of multivalued mappings," Applied Mathematics Letters, vol. 22, no. 9, pp. 1364-1368, 2009.

[19] N. Shahzad and H. Zegeye, "On Mann and Ishikawa iteration schemes for multi-valued maps in Banach spaces," Nonlinear Analysis: Theory, Methods \& Applications, vol. 71, no. 3-4, pp. 838-844, 2009.

[20] W. Cholamjiak and S. Suantai, "A hybrid method for a countable family of multivalued maps, equilibrium problems, and variational inequality problems," Discrete Dynamics in Nature and Society, vol. 2010, Article ID 349158, 14 pages, 2010.

[21] S. Hong, "Fixed points of multivalued operators in ordered metric spaces with applications," Nonlinear Analysis: Theory, Methods \& Applications, vol. 72, no. 11, pp. 3929-3942, 2010.

[22] S. H. Khan, I. Yildirim, and B. E. Rhoades, "A one-step iterative process for two multivalued nonexpansive mappings in Banach spaces," Computers \& Mathematics with Applications, vol. 61, no. 10, pp. 3172-3178, 2011.

[23] S. Saewan and P. Kumam, "Modified hybrid block iterative algorithm for convex feasibility problems and generalized equilibrium problems for uniformly quasi- $\phi$-asymptotically nonexpansive mappings," Abstract and Applied Analysis, vol. 2010, Article ID 357120, 22 pages, 2010.

[24] J. Schu, "Weak and strong convergence to fixed points of asymptotically nonexpansive mappings," Bulletin of the Australian Mathematical Society, vol. 43, no. 1, pp. 153-159, 1991.

[25] L. S. Liu, "Ishikawa and Mann iterative process with errors for nonlinear strongly accretive mappings in Banach spaces," Journal of Mathematical Analysis and Applications, vol. 194, no. 1, pp. 114-125, 1995.

[26] H. K. Xu, "Iterative algorithms for nonlinear operators," Journal of the London Mathematical Society, vol. 66, no. 1, pp. 240-256, 2002. 




Advances in

Operations Research

mansans



The Scientific World Journal



Submit your manuscripts at http://www.hindawi.com


Journal of

Function Spaces

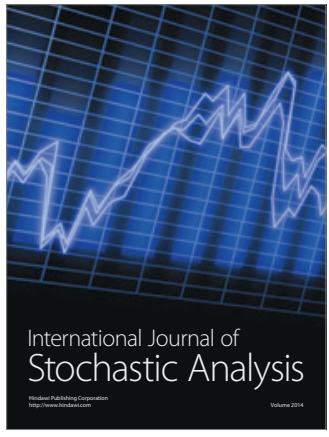

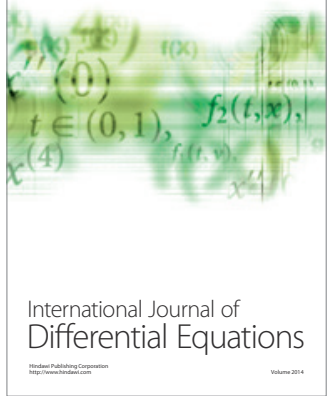
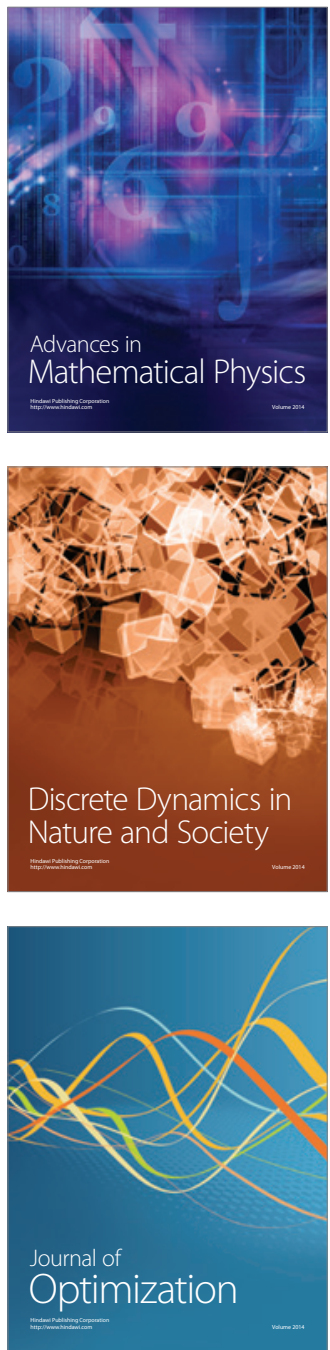